\title{
FATIGUE CRACK GROWTH AT THE REPRESENTATIVE ZONES IN FRICTION STIR WELDING OF A HEAT-TREATABLE ALUMINIUM ALLOY AT $200^{\circ} \mathrm{C}$
}

\author{
Tran Hung Tra \\ Nha Trang University, 2 Nguyen Dinh Chieu, Nha Trang, Viet Nam \\ Email:tra@ntu.edu.vn \\ Received: 16 June 2017; Accepted for publication: 6 November 2017
}

\begin{abstract}
Aluminium alloy 6063-T5 plates were joined by friction stir welding technique. The fatigue crack growth (FCG) in the thermo-mechanical affected zone (TMAZ) and in the heat affected zone (HAZ) of the welding was examined at $200{ }^{\circ} \mathrm{C}$. Although the grain microstructure of the TMAZ was significantly refined in comparison with that of BM, the FCG rate in TMAZ and base metal was shifted a comparable amount when the test temperature was elevated from room temperature to $200{ }^{\circ} \mathrm{C}$. In the metallurgical view, the $\mathrm{FCG}$ rate in the fine grain TMAZ was higher than that in coarse grain HAZ and base metal site.
\end{abstract}

Keywords: aluminum alloy 6063-T5, friction stir welding, fatigue crack growth, HAZ, TMAZ, high temperature.

Classification numbers: 5.1.4; 5.4.6.

\section{INTRODUCTION}

Aluminium alloys are one of the key materials possessing several advantages such as light weight, relatively low cost, heat treatable, high specific strength. Thus these alloys have been applied in the wide range of applications, especially in the aviation field [1]. However, one of the most challenges in using these alloys associates with their welding. Friction stir welding (FSW) is emerging as a preeminent technology for solving this obstacle. This FSW is suitable for joining light weight alloys such as aluminium alloys for both similar and dissimilar welding $[2,3]$. Furthermore, this FSW is recognized as a green technique in metal joining with high energy efficiency and versatility. This welding technique has been found to be a key joining technology in the near future. Since the welding can be obtained at the temperature below the melting point and thus it can be used to join the alloys which recognized to be unweldable by traditional fusion welding methods. However, it is well known that the FSW is thermomechanical processing and the result of severe plastic deformation and microstructure changes. The welded zone possesses various inhomogeneous microstructure features and mechanical properties [4,5]. With aluminium alloy 6063, a heat-treatable alloy, beside the microstructure is recrystallized severely during welding, the effect of temperature on mechanical properties during 
welding and/or during testing is unavoidable. In fact, during the welding process, the FSW temperature in AA6065-T5 is up to $550{ }^{\circ} \mathrm{C}$ [4], significantly higher than that of the dissolution point of this alloy (about $250{ }^{\circ} \mathrm{C}$ [5]). Furthermore, it is well known that the test temperature significantly influences on fatigue crack growth (FCG) rates that deal with microstructural evolutions, mechanical property changes, and/or residual stress relaxation [6 - 9]. In order to explore the effect of the elevated temperature on the FCG resistance in the representative areas in and around the FSW of AA6063-T5, two objective areas are addressed in which one is located in the heat affected zone outside the stirred zone and another is located in the thermo-mechanical affected zone or the stirred zone. The FCG result is compared to that of base metal (BM). The FCG tests were performed at $200{ }^{\circ} \mathrm{C}$ and the FCG rates are compared with those tested at room temperature (RT). The microstructure, the hardness, and residual stress in and around the welded zone are considered.

\section{EXPERIMENTAL PROCEDURES}

The butt-welded joints of AA6063-T5 with $5.0 \mathrm{~mm}$ thickness were fabricated by friction stir technique using a NC milling machine. The weld tool geometry applied in this work is a scrolled shoulder tool and a truncated cone pin with the pin diameter of $5.0 \mathrm{~mm}$ at the middle pin length, the pin height of $4.5 \mathrm{~mm}$, and the screw pitch of $1.0 \mathrm{~mm}$. The pin was aligned at a tilt angle of $2.0 \mathrm{deg}$. In the plane containing the pin axis and center weld line. The tool tip was kept at a distance of $0.2 \mathrm{~mm}$ from the backing anvil. Various regimes of weld parameters were performed by combining the tool rotation speed and the weld speed. An optimized FSW joint was selected by relying on its highest tensile properties and was used to conduct the FCG tests. From a $5.0 \mathrm{~mm}$ welded plate, transverse center notched fatigue specimens were extracted perpendicular to welding direction so that the loading axis of the fatigue test and the crack propagation direction are transverse and longitudinal to the welding direction, respectively (Figure 1). In this work, the FCG in two objective areas in the welding was addressed; those were the heat affected zone (named HAZ) and the thermo-mechanical affected zone or stirred zone (named TMAZ). The former possessed a comparable grain microstructure and the later possesses a fine microstructure in comparison with the BM. For the FCG test purpose, an initial notch of each FCG specimen was introduced in the HAZ (at $8.5 \mathrm{~mm}$ apart from weld center) and in the TMAZ (at weld center) by electro discharge machining, as illustrated in Figure 1. The length and radius of notch were $7.0 \mathrm{~mm}$ and $0.1 \mathrm{~mm}$, respectively. The FCG in the base metal site was also tested for comparative purpose. The FCG tests were conducted at $200{ }^{\circ} \mathrm{C}$ and at RT in laboratory air at $25 \mathrm{~Hz}$ load frequency and loading ratio $R=0.1$ by means of a servo-hydraulic testing machine, followed the ASTM E647 standard [10]. The length of cracks was monitored from both sides of the specimen surface by means of a traveling microscope. Residual stress in and around the weld zone was measured by X-ray diffraction (XRD) $\sin ^{2} \Psi$-method, following the Standard Method for X-ray Stress Measurement proposed by The Society of Materials Science of Japan [11]. Residual stress measurements were collected at a Bragg angle of 139.5 deg. Corresponding to diffraction at the (311) planes. The hardness in and around the welded zone of as-welded and tested specimens is measured by a diamond indentation with $50 \mathrm{~g}$ loading and $10 \mathrm{sec}$. hold time. The microstructure is observed by scanning electron microscope (SEM). 


\section{EXPERIMENTAL RESULTS AND DISCUSSION}

After fabricated, the microstructure in the welding was mechanically polished and chemically etched to observe the microstructure in and around the welded zone. The microstructure in the thermo-mechanical stirred zone was refined remarkably (Figure 2a). Grain size in the HAZ was comparable to that of base metal (BM), see Figure $2 \mathrm{~b} \& \mathrm{c}$. The residual stress was measured in a diffracted area of $2 \times 2 \mathrm{~mm}^{2}$ on the specimen surface after electropolished. Attention was paid to HAZ and TMAZ where correlate with the FCG areas. Here the residual stress component which parallels to the fatigue loading direction was measured. The residual stress in HAZ and in TMAZ is quite small and it is tensile in HAZ $(+13.1 \mathrm{MPa})$ and compressive in TMAZ $(-1.5 \mathrm{MPa})$. Further, the residual stress component which perpendicular to the fatigue loading direction was also measured for reference purpose. This component of residual stress in HAZ and in TMAZ was also quite small and it is compresive in HAZ (-5.2 MPa) and tensile in TMAZ (+4.8 MPa). Each value of the residual stress was averaged from the three measurements. This residual stress result provided an important view that this FSW joint possesses a quite low residual stress. Here, the residual stress in this welding is below $10 \%$ of the parent metal yield stress and this value is hardly to be obtained by the fusion welding techniques. A local softened zone in the FSW was formed after welding and it became softened uniform after tested at $200{ }^{\circ} \mathrm{C}$.

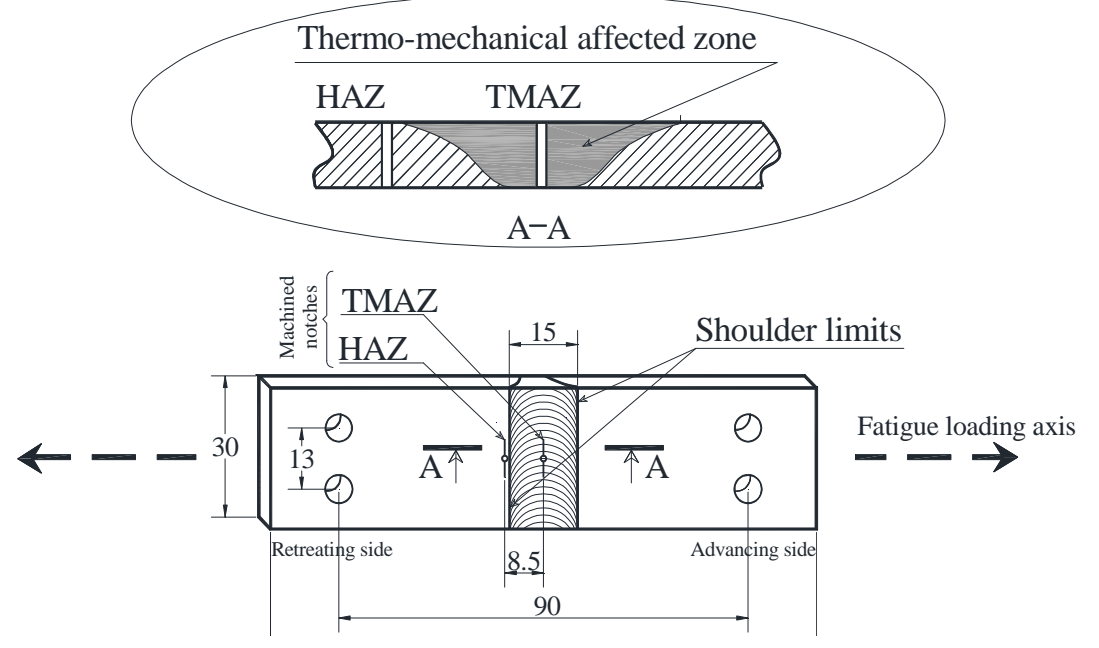

Figure 1. Geometry of the specimen used and the notch locations.

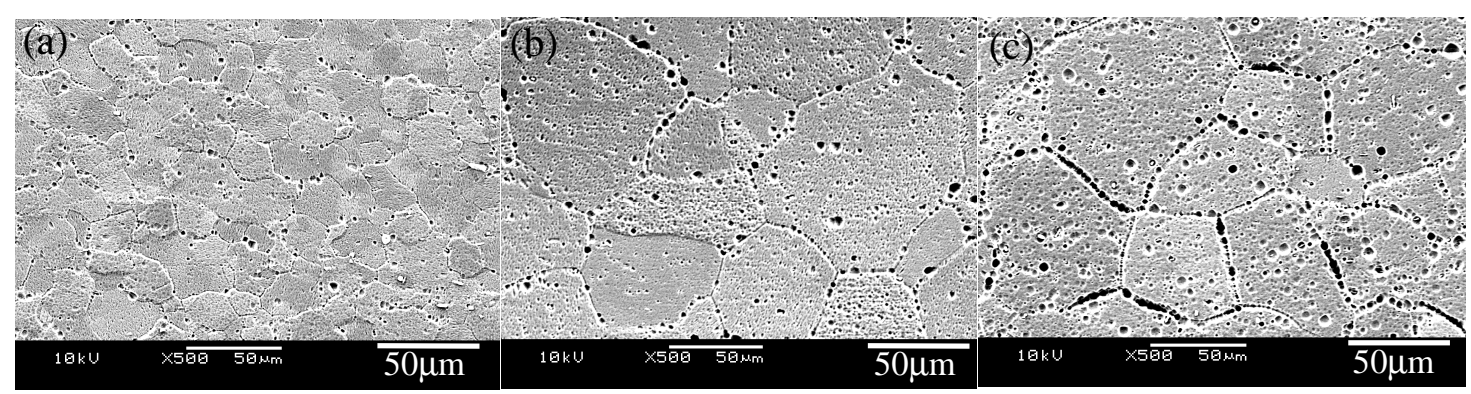

Figure 2. Microstructure in the cross section of FSW (a) in TMAZ, (b) in HAZ, and (c) in base metal site. 
The results of FCG tests were presented on the relationship between FCG rate, $d a / d N$, and stress intensity factor range, $\Delta K$, in which $\Delta K$ was calculated by an equation applied for the center notch FCG specimen followed the ASTM E647 standard [10]. The results of the FCG at $200^{\circ} \mathrm{C}$ compared to that at RT in each zone, including BM are presented in Figs. 3-5. The FCG rate in TMAZ and in HAZ compaed to that in the BM site at $200^{\circ} \mathrm{C}$ is displayed in Figs. $6 \& 7$.

The degraded fatigue strength of the parent material AA6065-T5 under the elevated temperature can be seen in Figure 3, where the FCG rate of the BM site tested at $200^{\circ} \mathrm{C}$ is about a half order higher than that done at RT. In Figure 4 shows FCG resistance (ability to resist the crack growth) in TMAZ is also degraded in a similar amount with that in BM site. Whilst the FCG behavior in TMAZ and in BM shows an usual manner, it becomes unusual in HAZ. Here the FCG rate in HAZ is significantly decreased when the test temperature is elevated to $200^{\circ} \mathrm{C}$. The rate in the $\mathrm{HAZ}$ tested at $200^{\circ} \mathrm{C}$ is about half order lower than that done at RT (see Figure 5). Interestingly, the elevated temperature test seems to enhance the FCG resistance in this joint. The results of the FCG at the elevated temperature in TMAZ and in HAZ tested at $200^{\circ} \mathrm{C}$ and compared with that in BM in the same test condition (see Figure 6). It can be seen that while the FCG rate in TMAZ is about a half order higher than that in BM, that in HAZ is comparable to that in BM site (see Figure 6).

In the mechanical view, the effect of the residual stress and the non-uniform mechanical properties across the weld must be considered. The role of the dissolution and/or coarsened precipitates in the FCG rate of the FSW was studied in the previous work [12] and founded that it has a minor effect. The residual stress in TMAZ was measured and found that it was in compression and quite small $(-1.5 \mathrm{MPa})$. This value of residual stress is believed to have no effect on the FCG rate in TMAZ under both tested temperatures. Obviously from this view, the role of the mechanical factors in the FCG rate in TMAZ is insignificant. In the metallurgical view, the elevated temperature accelerated the FCG rate in TMAZ and in BM with a comparable amount, see Figure 7, even thought they possesed a remarkable different microstructure feature as seen in Figure 2.

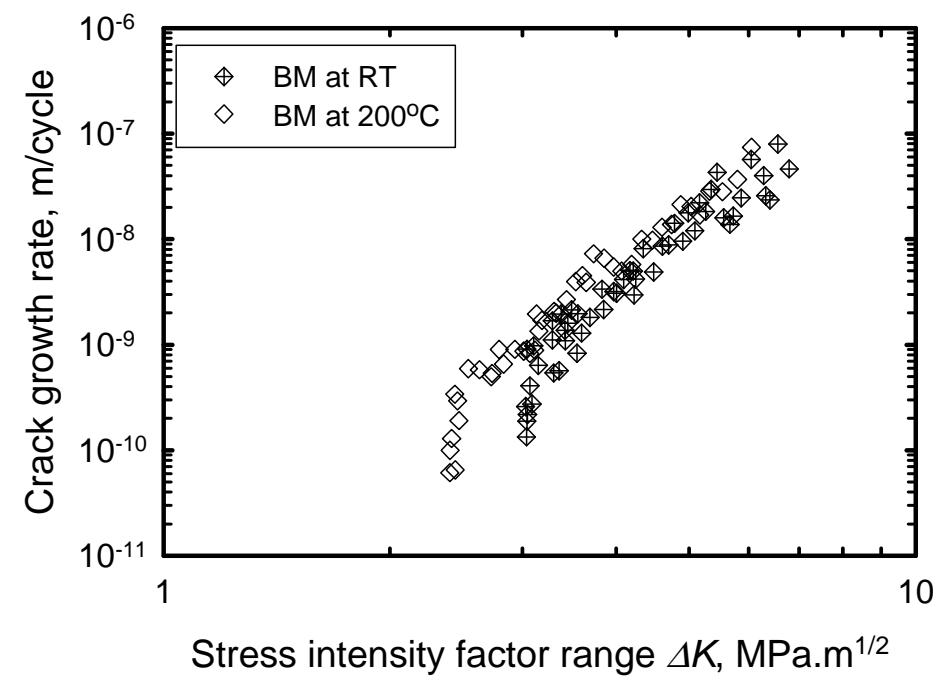

Figure 3. Fatigue crack growth rates in BM at RT and $200{ }^{\circ} \mathrm{C}$. 


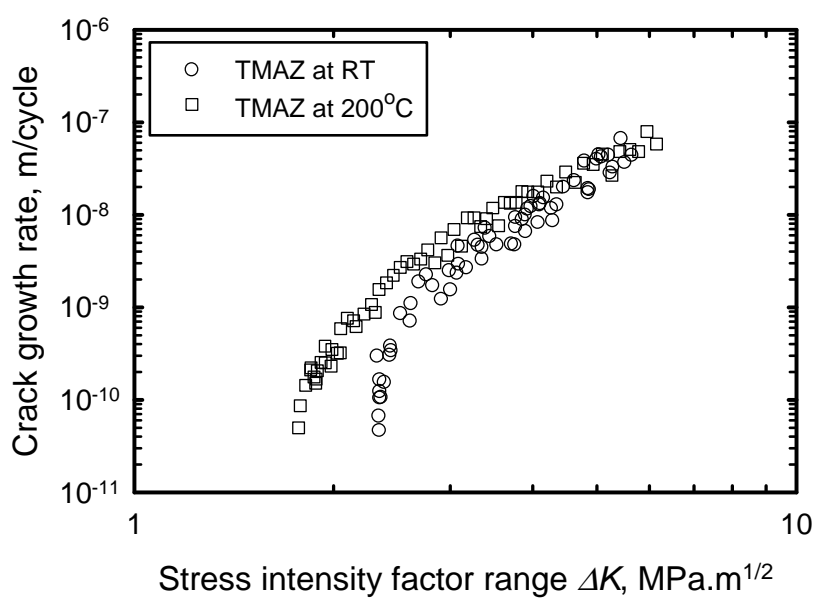

Figure 4. Fatigue crack growth rates in TMAZ at RT and $200{ }^{\circ} \mathrm{C}$.

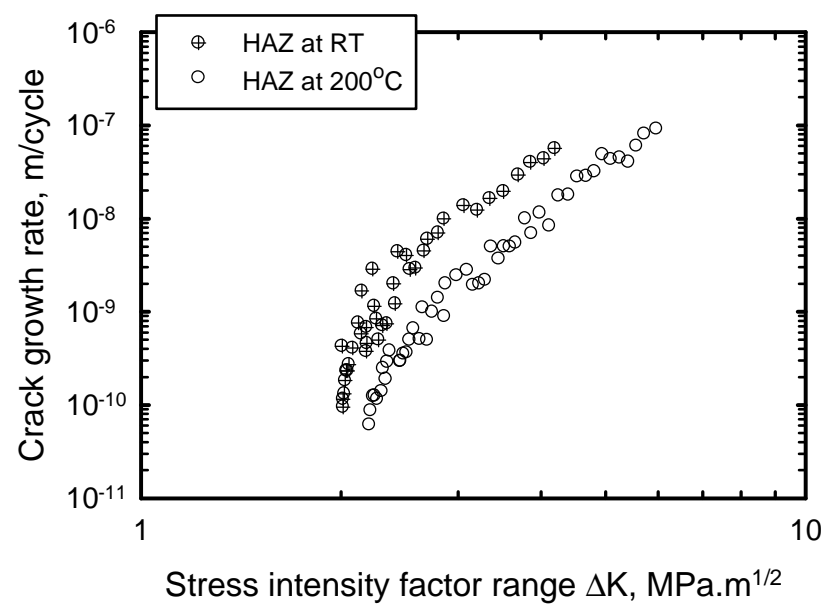

Figure 5. Fatigue crack growth rates in $\mathrm{HAZ}$ at $\mathrm{RT}$ and $200^{\circ} \mathrm{C}$.

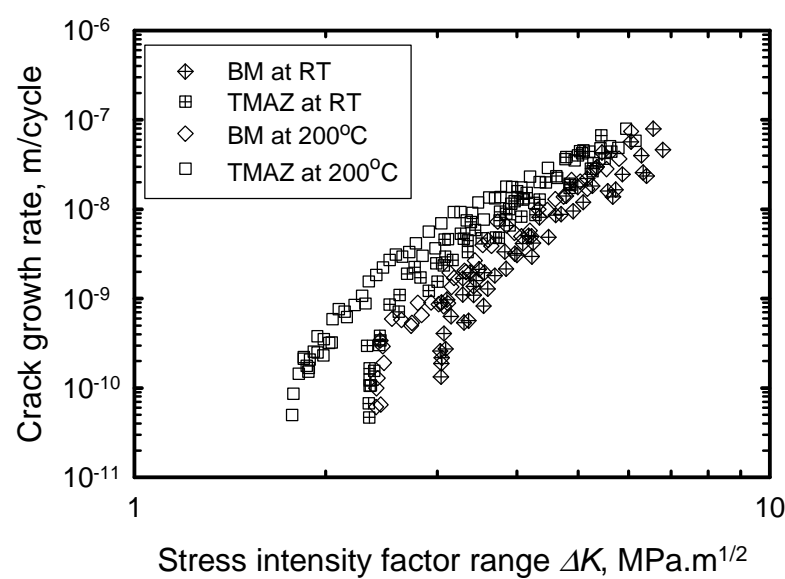

Figure 6. Fatigue crack growth rates in $\mathrm{SZ}$ and in $\mathrm{BM}$ under $\mathrm{RT}$ and $200^{\circ} \mathrm{C}$. 


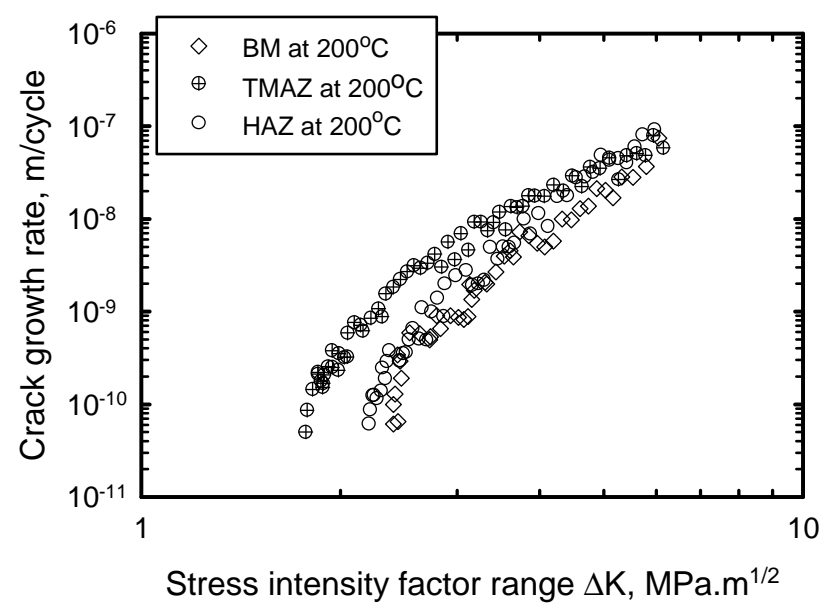

Figure 7. Fatigue crack growth rates in TMAZ, HAZ and BM at $200^{\circ} \mathrm{C}$.

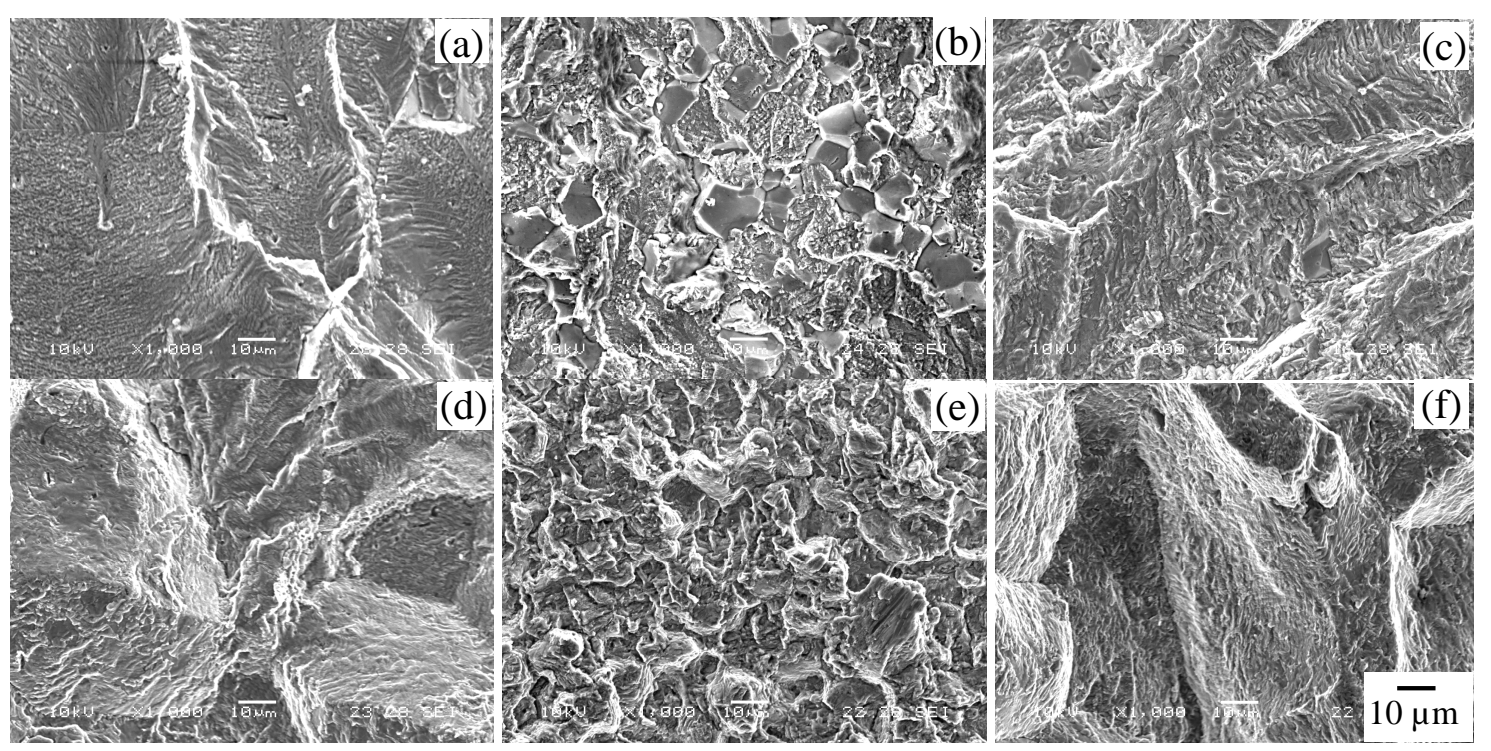

Figure 8. Fracture surfaces of (a) BM at RT, (b) TMAZ at RT, (c) HAZ at RT,

(d) $\mathrm{BM}$ at $200^{\circ} \mathrm{C}$, (e) $\mathrm{TMAZ}$ at $200^{\circ} \mathrm{C}$, and (f) $\mathrm{HAZ}$ at $200^{\circ} \mathrm{C}$.

In the HAZ, the role of the residual stress is considered. The residual stress in HAZ of the virgin FSW was measured and it is found to be in tension and approximate to $13.5 \mathrm{MPa}$ [12]. This tensile residual stress is believed to enhance the FCG rate in HAZ. When the HAZ is tested at $200{ }^{\circ} \mathrm{C}$, the residual stress release occurred and leaded to the reduction of the FCG rate in HAZ as seen in Figure 5. Furthermore, this residual stress is considered to be low (below ten percent of the base metal yield stress) and this residual stress is expected to be mostly released at $200{ }^{\circ} \mathrm{C}$ test. The results in Figure 6 showed clearly that the FCG resistance in HAZ and in BM is quite comparable at the elevated temperature. Further, it should be noted that the grain microstructure in the HAZ is comparable with that in BM (see Figure 2b\&c). The effect of the dissolution and/or coarsening of the precipitates on the FCG rates in this FSW is found to be tiny 
[12]. From this view, it can be inferred that the effect of the elevated temperature on HAZ and on $\mathrm{BM}$ is similar.

Figure 8 presents the fracture surface in HAZ, in TMAZ and in BM site under two tested temperatures, RT and $200{ }^{\circ} \mathrm{C}$. It can be seen whilst the fracture surface in $\mathrm{HAZ}$ and in $\mathrm{BM}$ is viewed in a common feature, it is quite special in TMAZ. Here, the fracture surface in TMAZ with fine microstructure associates with some intergranular fracture feature whereas it associates with a dominant transgranular feature in $\mathrm{HAZ}$ and in BM. This special feature on the fracture surface of TMAZ migh associate with the lower FCG resistance in the TMAZ in comparison with that of BM and HAZ under elevated test temperature.

\section{CONCLUSIONS}

The effect of the elevated test temperature on the FCG in the TMAZ and HAZ of AA6063T5 FSW joints was studied. The FCG rate in each zone was sensitive to the test temperatures. Eventhougt the TMAZ possessed a fine grain microstructure, the FCG rate in this zone was higher than that in the coarse grain zones. The role of the residual stress kept a important role in the different behavior in TMAZ and HAZ. In the metallurgical view, the influence of the elevated temperature on the FCG rate on the recrystallized TMAZ and BM site was similar. At $200{ }^{\circ} \mathrm{C}$ test, FCG rate in HAZ was comparable with that in BM, the rate in TMAZ was about a haft order higher than that in BM.

Acknowledgements. I am grateful to Prof. Masakazu Okazaki for several hours of his advices. I also thanks to Prof. Kenji Suzuki for his residual stress measurement support.

\section{REFERENCES}

1. Tolga D., Costas S. - Recent developments in advanced aircraft aluminium alloys. Materials \& Design 56 (2014) 862-871.

2. Amini A., Asadi P., Zolghadr P. - Friction stir welding applications in industry. Advances in Friction-Stir Welding and Processing, A volume in Woodhead Publishing Series in Welding and Other Joining Technologies (2014) 671-722.

3. Akinlabi E.T., Akinlabi S.A. - Friction stir welding of dissimilar metals. Advances in Friction-Stir Welding and Processing, A volume in Woodhead Publishing Series in Welding and Other Joining Technologies (2014) 241-293.

4. Tra T.H. - Effect of weld parameters on the mechanical properties of friction stir welding AA6063-T5. ASEAN Engineering Journal 4 (2011) 73-81.

5. Sato Y.S., Kokawa H., Enomoto M., Jogan S., and Hashimoto T. - Precipitation Sequence in Friction Stir Weld of 6063 Aluminum during Aging. Metallurgical and Materials Transactions A 30 (12) (1999) 3125-3130.

6. Rao K.P., Prasad Y.V.R.K. - High temperature deformation kinetics of Al-4Mg alloy. Journal of Mechanical Working Technology 13 (1) (1986) 83-95.

7. Ralph I., Srephens, Fatemi A., Stephens R.R., Fuchs H.O. - Metal fatigue in Engineering, John Willey \& Son INC, 2001. 
8. Ma Y. E., Xia Z.C., Jiang R. R., Li W. - Effect of welding parameters on mechanical and fatigue properties of friction stir welded 2198 T8 aluminum-lithium, Engineering Fracture Mechanics 114 (2013) 1-11.

9. Suresh S. - Fatigue of Materials, Cambridge University Press, 1998.

10. Annual book of ASTM standards, 2003, (03.01), pp. 615-657.

11. Standard Method for X-ray Stress Measurement, The Society of Materials Science of Japan, 2005.

12. Tra T. H., Okazaki M., Suzuki K. - Fatigue crack propagation behavior of friction stir welding AA 6063-T5: Role of residual stress and microstructure. International Journal of Fatigue 43 (2012) 23-29. 